\title{
Cervical diameter in relation to uterine and cervical EMG activity in early postpartum dairy cows with retained placentas after PGF2alpha induced calving
}

\author{
E. van Engelen ${ }^{\mathrm{a}, *}$, M.A.M. Taverne ${ }^{\mathrm{b}}$, M.E. Everts ${ }^{\mathrm{a}}$, G.C. van der Weijden ${ }^{\mathrm{b}}$, \\ A. Doornenbal ${ }^{\text {a }}$, V.N.A. Breeveld Dwarkasing ${ }^{\text {a }}$ \\ ${ }^{a}$ Department of Pathobiology, Faculty of Veterinary Medicine, Utrecht University, P.O. Box 80.158, 3508 TD Utrecht, The Netherlands \\ ${ }^{\mathrm{b}}$ Department of Farm Animal Health, Faculty of Veterinary Medicine, Utrecht University, P.O. Box 80.151, 3508 TD Utrecht, The Netherlands
}

Received 21 December 2006; received in revised form 25 April 2007; accepted 25 April 2007

\begin{abstract}
The cervix must regain its normal diameter after parturition. Until now, little has been known about the pattern of cervical closure and the possible influences of myometrial and cervical contractions in this process. We continuously measured the cervical diameter with ultrasound cervimetry during the first $48 \mathrm{~h}$ after calving in six cows with retained fetal membranes, while uterine $(n=6)$ and cervical outer muscular layer $(n=4)$ electromyographic (EMG) activity was measured with bipolar EMG electrodes.

We found that the cervical diameter which was $6.2 \mathrm{~cm}( \pm 0.7)$ at $1.4 \mathrm{~h}$ after calving, initially increased to $9.0 \mathrm{~cm}( \pm 1.0)$ during the first $14.8 \mathrm{~h}( \pm 2.8)$ postpartum. After this time, the diameter decreased gradually to $5.3 \mathrm{~cm}( \pm 1.0)$ at $48 \mathrm{~h}$ after calving. The overall EMG activity after parturition decreased by $59 \%( \pm 6)$ and $35 \%( \pm 17)$ for the uterus and cervix, respectively. The decrease in EMG activity was due to a 50\% $( \pm 7)$ decrease in EMG amplitudes of the myometrium; the EMG amplitudes of the cervix decreased by only $8 \%( \pm 21)(P>0.05)$. At the same time in the cervix, burst frequency decreased by $69 \%( \pm 17)$, while the decrease in burst frequency of the myometrium was only $11 \%( \pm 5)(P>0.05)$.

Uterine myometrial and cervical EMG activity after parturition showed burst patterns. These contractions of the uterus and cervix were accompanied by and correlated with transient dilatations of the caudal cervix. This could have functional relevance in the evacuation of the uterus.
\end{abstract}

(C) 2007 Elsevier Inc. All rights reserved.

Keywords: Cervix; Postpartum; EMG activity; Bovine; Myometrium

\section{Introduction}

During pregnancy, the uterine cervix is firm and closed due to a high content of connective tissue which is dispersed with and surrounded by bundles of smooth muscle cells [1]. Shortly before and during parturition, the connective tissue of the cervix is remodelled [2-4]

\footnotetext{
* Corresponding author. Tel.: +31 30253 5252; fax: +31 302539233 .

E-mail address: e.vanengelen@vet.uu.nl (E.van Engelen).
}

and loses its strength [5] which results in a softened cervix that is able to dilate and accommodate the fetus when the uterus contracts [6]. The cervix is an important barrier against the invasion of bacteria in the uterine cavity $[7,8]$. Therefore, it is obvious that closure of the cervical canal and regaining of its firm structure after parturition is important for a successful new pregnancy. When this process is incomplete or delayed, as is the case in cows with retention of the placenta, it predisposes to the development of endometritis $[7,8]$. Insufficient closure of the cervix thus leads to infertility or even sterility in cows [9] and mares [10]. 
It is evident that contractions of the pregnant uterus are involved in the dilatation of the cervix during parturition $[6,11]$ and that equally strong and even more frequent uterine contractions are present immediately after delivery of the calf [12-21]. After uncomplicated calvings, the frequency of these contractions decreases to almost zero within 2 days $[13,20]$. In cows with retained membranes however, both the frequency and the amplitude of uterine contractions have been reported to remain high for at least more than 2 days $[13,20]$. One could question whether these postpartum uterine contractions in any way interfere with closing of the cervix.

The cervix shows considerable amounts of electromyographic (EMG) activity immediately after parturition which decreases to low levels between 48 and $72 \mathrm{~h}$, as has been shown in sheep [22]. It could be expected that these postpartum contractions of the cervix itself influence cervical diameter which could either be a decrease or an increase of the cervical diameter, as both phenomena have been described during parturition $[23,24]$.

Given the importance of cervical closure for a good reproductive performance, it is remarkable that neither cervical closure, nor possible influences of uterine or cervical contractility have been explored more extensively. A better understanding of the factors that influence cervical closure would lead to a more evidence based diagnosis and intervention in cases in which this closure is impaired. In fact, there is only one report describing the process of cervical closing in cows during the first 10 days postpartum [25]. In that study, a forceps was repeatedly inserted in the genital tract. It was observed that a decrease in cervical diameter from 25 to $5.2 \mathrm{~cm}$ takes place within the first 2 days. However, no information on uterine or cervical contractility was provided in that study.

The study has the following three aims: (1) to describe the cervical diameter during the first $48 \mathrm{~h}$ postpartum in cows with retained placentas; (2) to compare cervical with uterine EMG activity during that time period; (3) to analyze the relationship between the EMG activity and the cervical diameter. We hypothesize that the cervical diameter, with an initial diameter of about $25 \mathrm{~cm}$, decreases steadily during the first 2 days after calving, and that uterine and cervical EMG activity causes temporal changes in cervical diameter.

For this purpose, cervical diameter was measured continuously with ultrasound while EMG activity of the myometrium and cervix were recorded during the first $48 \mathrm{~h}$ after calving. This paper presents the results of a study that was performed on cows that previously had been used in an experiment in which the cervical diameter and EMG activity of the myometrium and cervix were recorded during a parturition which was induced with a synthetic PGF $2 \alpha$ analogue [24]. As a consequence of the use of PGF $2 \alpha$ all the cows had retained placentas, due to insufficient shedding of the cotyledons from the caruncles [20], after otherwise normal calvings.

\section{Materials and methods}

\subsection{Animals and surgery}

Six pluriparous Holstein Friesian (HF) cows, bred by HF bulls, were purchased from farmers at 6-7 months of pregnancy. They were selected on the following traits: a body condition score of 3-3.5 [26], only spontaneous uncomplicated parturitions in their history and carrying a singleton pregnancy with an anterior presentation. Six cows were deemed to be sufficient for this study, based on previous studies using similar physiological parameters and experimental protocol [14,15,24,27]. The use of these animals in this experiment which was a follow-up of a previously described study [24] had been approved by the Ethical Committee of the Veterinary Faculty of Utrecht University (The Netherlands). The cows were housed in individual stands in the clinical facilities of the veterinary faculty from their arrival until the start of the experiments. They underwent surgery 10-14 days before parturition was induced with a synthetic PGF $2 \alpha$ analogue (Prosolvin ${ }^{\circledR}, 2 \mathrm{ml}$ i.m., Intervet, Boxmeer, The Netherlands) on day 274 of pregnancy. The surgical procedure has been extensively outlined previously [24,27]. Briefly, during abdominal surgery, two bipolar $\mathrm{AgAgCl}$ electrodes, made in our own laboratory with $5 \mathrm{~mm}$ distance in between [28], were sutured on the surface of the uterine myometrium near the top of the uterine horn. A bipolar fishhook-like stainless steel electrode, prepared from two stainless steel fishhooks, (Partridge of Redditch, UK) imbedded in epoxy with $5 \mathrm{~mm}$ distance in between, was attached on the middle dorsal surface of the cervical outer muscular layer. The wires, connected to the electrodes, were tunneled subcutaneously and exteriorized at the dorsal sublumbar area. The cows received flunixin meglumine (1 mg/kg i.v., Bedozane ${ }^{\circledR}$, Eurovet, Bladel, The Netherlands) for 2 days and ampicillin $(10 \mathrm{mg} / \mathrm{kg}$ i.m., Praxavet Ampi ${ }^{\circledR}$, Boehringer-Ingelheim, Alkmaar, The Netherlands) for 5 days. They had free access to food and water, and after two days of recovery the cows were placed in an individual pen $\left(3.1 \mathrm{~m}^{2}\right)$ to prevent them to reach the equipment and cables. 


\subsection{Experimental protocol}

The cows were under continuous video observation and none of them showed signs of dystocia. All cows delivered a healthy Holstein Friesian calf in anterior presentation, at an average interval of $38.8 \mathrm{~h}( \pm 3.4)$ after PG administration. Almost immediately after vaginal expulsion of the calf, two ultrasound transducers as manufactured and described by Eijskoot et al. [29], were sutured to the internal aspect of the caudal cervical rim. They were placed opposite to each other at 3 and 9 o'clock positions using a vaginal approach after caudal epidural anaesthesia had been applied to avoid abdominal straining during the procedure. One of the transducers functioned as transmitter and the other as receiver. The signals from the cervimeter were digitized with a multichannel analog/digital converter (National Instruments, Austin, USA), sampled with $40 \mathrm{~Hz}$ and stored with Labview 5.0 software (National Instruments, Austin, USA). After having sutured the transducers in place (at $1.2-1.9 \mathrm{~h}$ after birth of the calf), the cervical diameter and the EMG activity of the uterine myometrium and cervical muscular layer were measured continuously until $48 \mathrm{~h}$ after expulsion.

Because the cows were expected to retain their placenta, a capsule with tetracycline $(2 \mathrm{~g}$, Virbac, Barneveld, Netherlands) was manually placed in the formerly pregnant uterine horn, immediately after the ultrasound transducers had been sutured onto their position. The calves were removed from their mothers immediately after birth and the cows were milked twice per day. Each milking took only a few minutes and the data obtained during these short periods were included in the analysis.

The signals from the EMG electrodes were amplified with two amplifiers (model 11-4123-01; Gould Inc., Cleveland, OH or model UME-47; Schwarzer, München, Germany) and analog bandpass filtered from 0.05 up to more than $10 \mathrm{~Hz}$. All signals were subsequently digitized with a multichannel analog/digital converter, sampled with $40 \mathrm{~Hz}$ and stored with Labview 5.0 software. The data from the EMG activity recordings were digitally high-pass filtered $(0.125 \mathrm{~Hz})$ in Labiew to correct for slow fluctuations in tissue voltage.

\subsection{Data analysis and statistics}

\subsubsection{Cervical diameter}

The mean cervical diameter was calculated for consecutive $10 \mathrm{~s}$ periods. Plotting cervical diameter against time revealed two different stages: a first stage during which the cervical diameter did not decrease but

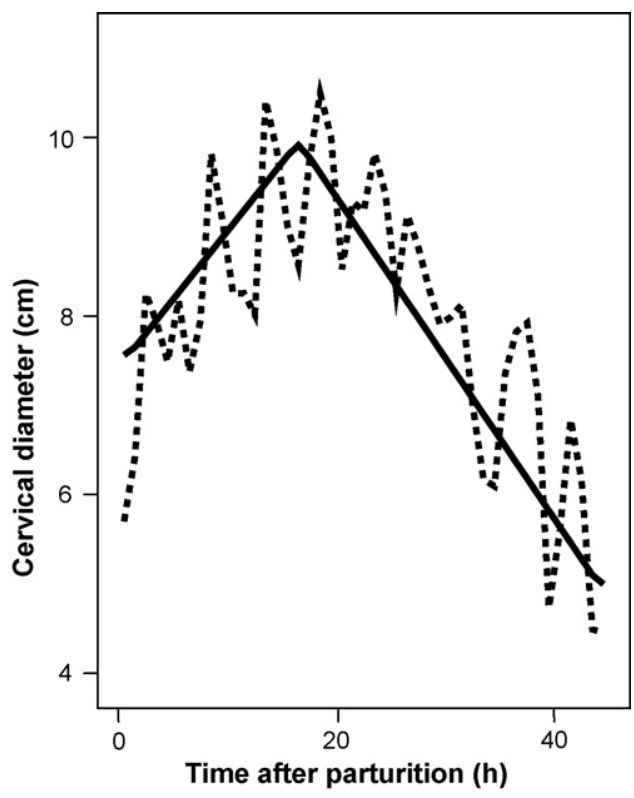

Fig. 1. An example of hourly means of measured values of cervical diameter in an individual cow (- - ), and calculated bi-linear regression lines (-). The bi-linear regression analysis was used to calculate the maximum cervical diameter and the time at which the maximum was reached.

in fact even increased to a maximum value, and a second stage during which the cervical diameter progressively decreased. This pattern was analyzed with bi-linear regression analysis in SPSS (Version 12.0.1, Chicago, USA, 2003) as previously described for the analysis of cervical dilatation in parturient cows [15]. The bi-linear regression analysis was used to calculate the time after delivery at which the postpartal cervix diameter reached its maximum and the magnitude of that maximum. As Fig. 1 exemplifies for one cow, the calculated values describe the raw data accurately. The parameters were first obtained for each cow separately, after which overall means ( \pm S.E.M., $n=6)$ were calculated.

\subsubsection{Uterine and cervical EMG activity}

The postpartum EMG activity pattern of the myometrium and cervix differed from ante partum and was characterized by well-defined bursts, alternated with periods of inactivity. As a result, we were able to analyze the EMG activity of the myometrium and cervix quantitatively using three different parameters.

Firstly, the total EMG activity was quantified by calculating the root mean square values (RMS) over consecutive $10 \mathrm{~s}$ periods. Due to the presence of noise, the RMS values appeared to have a basal level; this basal level was determined for each cow separately and 
subtracted from the values during the entire recordings. Secondly, the maximal positive EMG amplitude was determined for each consecutive $15 \mathrm{~min}$ period. Thirdly, the number of bursts of EMG activity was counted for each consecutive 15 min period.

The changes in the RMS values of EMG activity, the numbers of bursts and the maximal EMG amplitudes for the first $48 \mathrm{~h}$ after calving were further quantified with linear regression analysis in SPSS. The relative change in EMG activity was calculated by dividing the regression coefficients which reflected the changes in EMG activity over time, by the initial values of the EMG activity. The parameters were first obtained for each cow separately, after which overall means ( \pm S.E.M., $n=6$ ) were calculated. A one-sample $t$-test of the means of the individual cows was used to assess if there were significant changes in EMG activity over time. Values were regarded as statistically significant when $P$ was lower than 0.05 .

Additionally, the relationship between the occurrence of individual EMG bursts and transient changes in cervical diameter was analyzed. For this purpose, correlations were calculated between the RMS values of the EMG activity of the uterus and cervix and the cervical diameter. These correlations could be analyzed on two time scales. Firstly, the long-term relationship between the course of EMG activity and cervical diameter over the $48 \mathrm{~h}$ period. Secondly, the short-term relationship between individual bursts of EMG activity and simultaneously occurring changes in cervical diameter (temporal effects). Because we were primarily interested in the short-term correlation, it was necessary to eliminate the influence of the long-term correlations. This was done by correcting the correlation coefficients for time effect and cow effect, with the partial correlations method in SPSS.

\section{Results}

Each cow delivered a healthy calf in anterior position and retained the fetal membranes for more than 3 days. It took between 1.2 and $1.9 \mathrm{~h}$ after birth of the calf before the ultrasound transducers had been sutured to the caudal cervical rim, and the continuous measurements started. In two cows, the cervical muscular layer electrodes did not detect an EMG signal after calving, because they had become disconnected, probably due to damage during fetal expulsion. Examples of the original EMG activity of the myometrium and cervical muscular layer, as well as changes in the cervical diameter are given in Fig. 2 (all data obtained from the same cow at different time periods after calving).

\subsection{The cervical diameter}

The cervical diameter was $6.2 \mathrm{~cm}( \pm 0.7)$ at the start of the measurements which was on average at $1.4 \mathrm{~h}$ after expulsion of the calf (Fig. 3A). Quite unexpectedly, there were two stages to be recognized. With bi-linear regression analysis, we calculated that the first stage took $14.8 \mathrm{~h}( \pm 2.8)$, during which the diameter of the cervix increased $(P<0.05)$ to $9.0 \mathrm{~cm}( \pm 1.0)$; the second stage took $33.2 \mathrm{~h}( \pm 2.8)$, during which the cervical diameter decreased $(P<0.05)$ to $5.3 \mathrm{~cm}$ $( \pm 1.0)$ at $48 \mathrm{~h}$ after expulsion of the calf which was the arbitrarily chosen moment that we ceased the measurements. At that time the cervical diameter ranged between cows from 2.0 to $9.3 \mathrm{~cm}$.

\subsection{The EMG activity of the cervical muscular layer and myometrium}

Immediately after parturition both the myometrium $(n=6)$ and cervical muscular layer $(n=4)$ showed EMG activity which consisted of individual bursts with periods of rest in between. Bursts derived from the myometrium were uniform in duration and amplitude. Bursts from the cervical muscular layer however, were highly variable in duration and amplitude (Fig. 2A). Over time, the amplitudes of the EMG activity of the myometrium decreased to very low levels in all cows, but the amplitudes of the EMG activity of the cervical muscular layer did not clearly decrease. The frequency of bursts of the myometrium remained at about the same level during the $48 \mathrm{~h}$ period of the measurements (Fig. 2A-C) but in the cervical muscular layer, the frequency of bursts decreased over time.

The myometrium showed a total decrease of $59 \%$ $( \pm 6)(P<0.01)$ of the RMS values over the $48 \mathrm{~h}$ postpartum period (Fig. 3B). The cervical muscular layer however showed a total decrease of $35( \pm 17) \%$ $(P>0.05)$ of the RMS values (Fig. 3C).

Maximal EMG amplitudes of the myometrium decreased by $50 \%( \pm 7)(P<0.01)$ over the $48 \mathrm{~h}$ postpartum period (Fig. 4C). Maximal EMG amplitudes of the cervical muscular layer varied largely but did not change over time $(8 \%( \pm 21),(P>0.05))$, despite what may be suggested by Fig. 4D.

The myometrium showed a burst frequency of 19.8 per hour $( \pm 2.2)$ during the first hour of our measurement (Fig. 4A), after which it decreased by $11 \%( \pm 5)$ $(P>0.05)$ in total. The cervical muscular layer showed an initial burst frequency of 15.4 per hour $( \pm 1.3)$ (Fig. 4B), after which it decreased by $69 \%( \pm 17)$ 

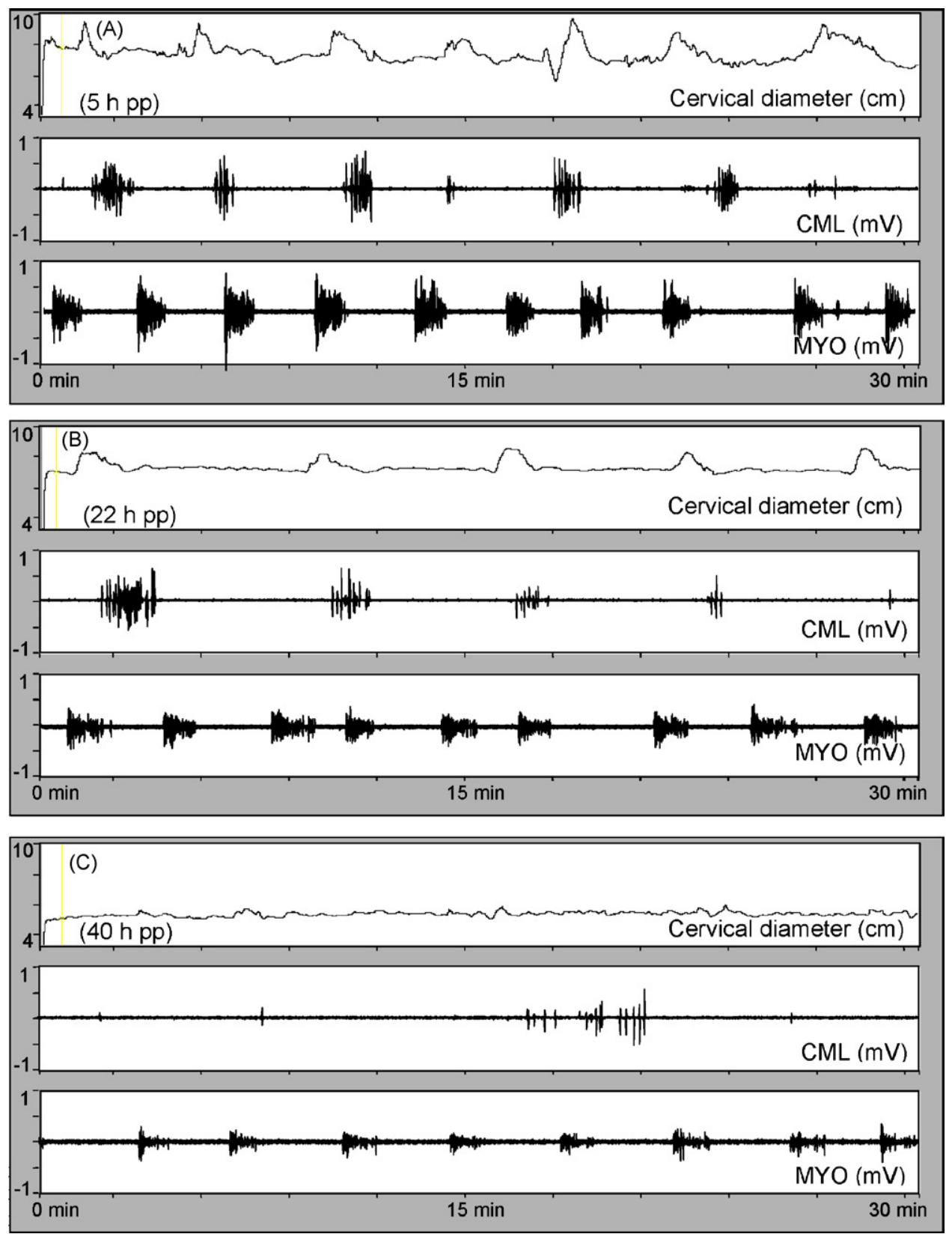

Fig. 2. Representative examples of 30 min recordings of the cervical diameter (cm) and EMG activity (mV) of the cervical muscular layer (CML) and myometrium (MYO) at: (A) $5 \mathrm{~h}$, (B) $22 \mathrm{~h}$ and (C) $40 \mathrm{~h}$ postpartum. The examples were derived from the same cow.

$(P<0.01)$. The mean burst frequency in the myometrium was higher than that in the cervical muscular layer. This difference became significant $(P<0.05$, repeated measures) from $29 \mathrm{~h}$ after parturition onwards. Despite this difference in mean burst frequencies, the bursts of both tissues showed synchrony, as mirrored by the positive correlation $0.178(P<0.001)$ between the RMS values of the two sites.

\subsection{The relationship between the EMG activity and cervical diameter}

In all cows, the cervical diameter increased transiently during EMG bursts throughout the first day postpartum, as illustrated for one cow in Fig. 2. These transient dilatations of the cervix occurred more often synchronously with a burst of the cervical 

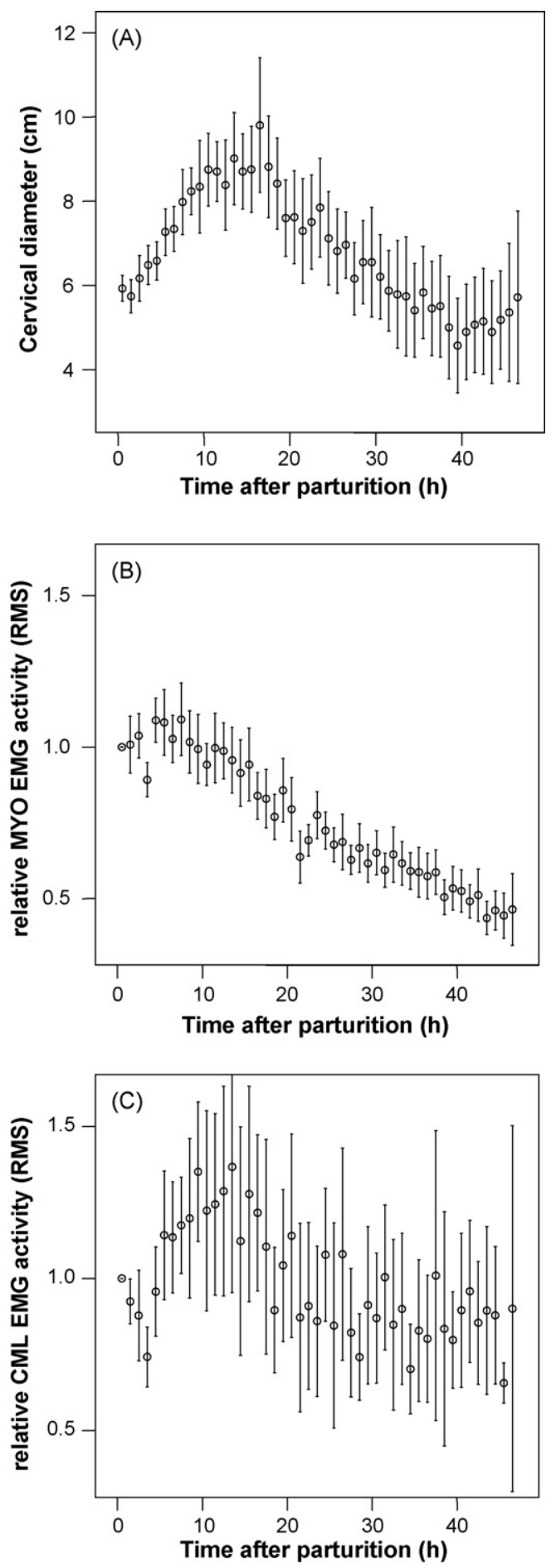

Fig. 3. Mean values per hour $( \pm$ S.E.M.) of cervical diameter $(\mathrm{cm})$ and EMG activity during the first $48 \mathrm{~h}$ after calving. (A) The cervical diameter $(n=6)$; (B) the EMG activity of the myometrium (MYO; $n=6$ ) expressed as RMS values; (C) the EMG activity of the cervical muscular layer (CML; $n=4$ ) expressed as RMS values. EMG activity is expressed relative to the values during the first hour of the measurements. Expulsion of the calf occurred at $t=0$. muscular layer than with a burst of the myometrium. During the second day postpartum not only did the baseline cervical diameter decrease but also the magnitude of the transient increases in cervical diameter. These temporal dilatations disappeared completely after $36.2 \mathrm{~h}( \pm 2.7)$.

The diameter of the cervix was positively correlated with the level of EMG activity (RMS values) in all cows. When the correlations ( $r$ ) were corrected for time effect, the correlation between the actual cervical diameter and the cervical muscular layer EMG activity was $0.255(P<0.001$, two-tailed analysis $)$ which was larger $(P<0.05)$ than the correlation between the actual cervical diameter and the myometrial EMG activity which was $0.168 \quad(P<0.001$, two-tailed analysis).

\section{Discussion}

\subsection{Diameter of the cervix}

Much to our surprise, the diameter of the caudal cervix had already markedly decreased to $6.2 \mathrm{~cm}$ at the beginning of our measurements, i.e. $1.4 \mathrm{~h}$ after calving. In three different studies, we have been able to measure the cervical diameter until the time that progression of fetal parts into the cervical canal disturbed the measurements. At that time, 15 out of 16 cows showed a cervical diameter of between 14 and $20 \mathrm{~cm}$. [15,24,27]. Also others described a cervical diameter of $20 \mathrm{~cm}$ at $1.5 \mathrm{~h}$ after spontaneous parturition [25]. Collagen breakdown is the main contributor to the increased softness of the cervix around parturition [2-4], but it would not be expected that in such a short time new collagen fibrils would have lead to stiffening of the once-flaccid tissue and contributed to this prompt recovery of the diameter. Besides collagen, the cervical stromal layer contains much smooth muscular tissue [24] which contracts under influence of oxytocin in vitro. Therefore, an active muscular component originating in the cervix could be responsible for this considerable decrease. Stretching of the cervical and vaginal tissues by the passage of the calf or the manipulations during suturing of the ultrasound transducers may have caused such muscular activity. However, we cannot verify this because no EMG data are available from the first $1.4 \mathrm{~h}$ after parturition. Another possible explanation could be that the initial decreased cervical diameter after calving is caused by a passive collapse of the flaccid walls of the cervical canal which is not occupied by the fetus anymore. Shortly after parturition, the caudal birth canal is distended. 
(A)
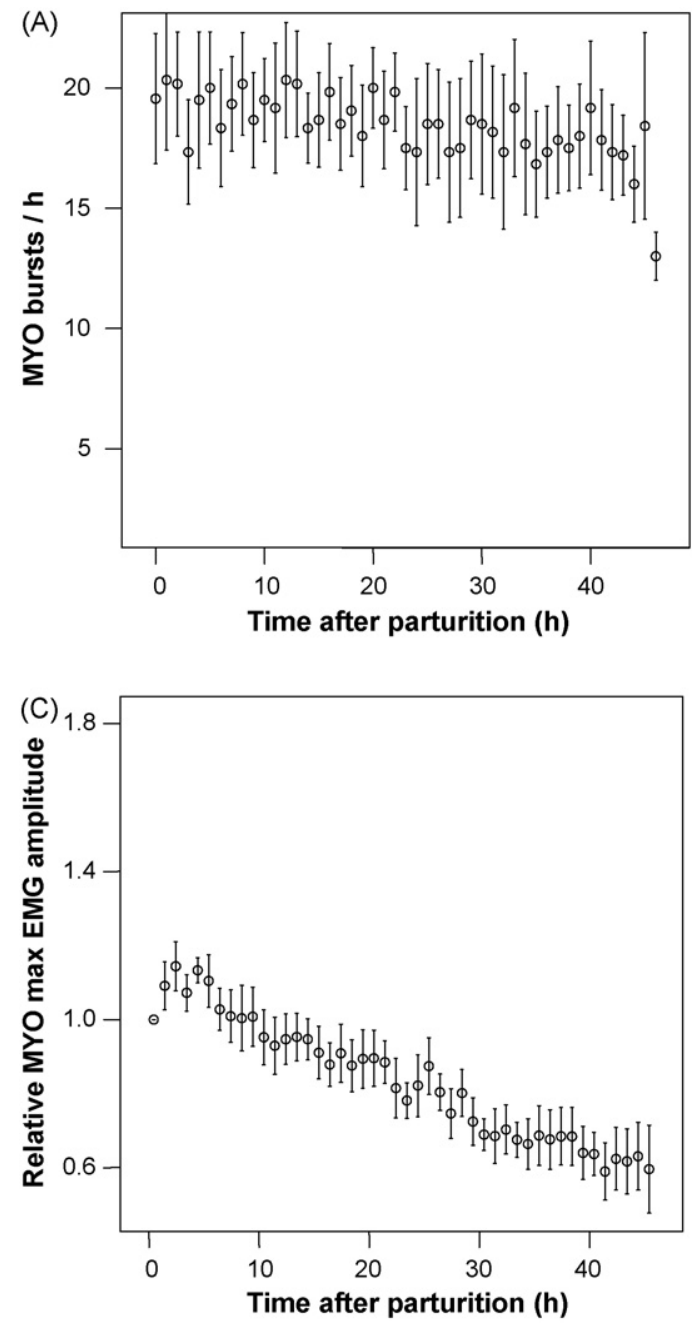
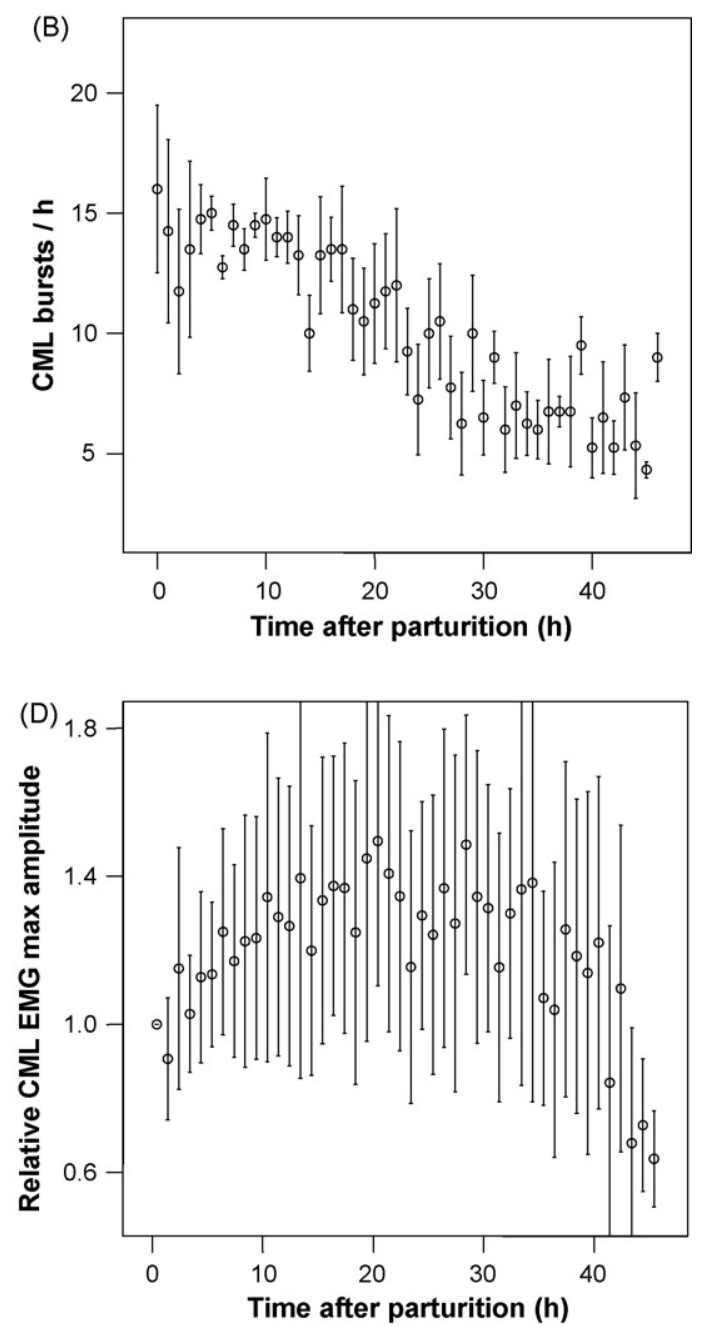

Fig. 4. Mean values ( \pm S.E.M.) of (A) burst frequency per hour of the myometrium; (B) burst frequency per hour of the cervical muscular layer; (C) maximal EMG amplitude of the myometrium and (D) maximal EMG amplitude of the cervical muscular layer. The data are obtained from continuous measurements of EMG activity of the myometrium (MYO; $n=6$ ) and the cervical muscular layer (CML; $n=4)$ during the first $48 \mathrm{~h}$ after calving. Values for maximal EMG amplitudes are expressed relative to the value for the first hour of the measurements. Expulsion of the calf occurred at $t=0$.

This leads commonly to aspiration of air, when the cow is in a standing position. Air becomes trapped in the vagina and uterus and might prevent cervical collapse. Normally the cow expells this air by uterine contractions and abdominal straining and this happens quite rapidly under influence of the high abdominal pressure when the cow is in a recumbent position. This expulsion of air may explain the rapid return of the cervical diameter to about $6 \mathrm{~cm}$, such as we have measured. On the other hand, repeatedly measuring the cervical diameter of early postpartum cows with calipers [25] which have to be introduced in the vagina while the cow is standing may cause aspiration of air repeatedly [30] which could explain why a diameter of $20 \mathrm{~cm}$ was measured by Wehrend et al. [25].
Even more unexpectedly the cervical diameter did not decrease further to a diameter smaller than $6 \mathrm{~cm}$, but instead it increased up to $9 \mathrm{~cm}$, during the first $15 \mathrm{~h}$ postpartum. Directly after a normal parturition, the uterus is empty, but still large in size. Thus, the placenta, with the placentomes still intact and attached to the uterine wall, lies far away from the cervix. Because the uterine cavity decreases rapidly in size after expulsion of the calf, the placenta comes more close to the cervix which is supported by our observation in two cows, that parts of the placenta became visible outside the vulva. The presence of the placenta could force the still soft and pliable cervix open. One may ask if an increase in cervical diameter also takes place in cows without placental retention; one would expect that the cervical 
diameter is increased at the time that the placenta is expelled, but such measurements have not yet been reported.

The cervical diameter started to decrease again at $15 \mathrm{~h}$ after parturition. During the period thereafter, the mean cervical diameter and the rate of its decrease are in accordance with the results of Wehrend et al. [25], who measured similar diameters in cows without retained placentas. During this stage, the presence of a retained placenta in our study seemed not to have influenced the cervical diameter any longer.

\subsection{The EMG activity of the cervical muscular layer and myometrium}

Although uterine and cervical EMG activity were correlated and both showed a decrease in RMS values during the first $48 \mathrm{~h}$ postpartum, cervical EMG activity also showed clearly several differences compared to uterine EMG activity. Firstly, the pattern of bursts in the cervical muscular layer was less well organized than in the uterus. The pattern of bursts of EMG activity of the myometrium was in accordance with previous reports for the postpartum period after PGF2 $\alpha$ induced calving [14]. These bursts are usually associated with contractions, as reflected by changes in intra uterine pressure $[14,31]$. The observation that the pattern of EMG activity of the cervical muscular layer appeared to be less well organized, corresponds with our findings in the same cows before fetal expulsion [24] as well as with findings in postpartum sheep [22]. Secondly, the decrease of the RMS values and maximal EMG amplitudes in the cervical muscular layer was less substantial than in the uterus and showed much variation between cows. RMS values and maximal amplitudes of the EMG activity both reflect the rate of synchronization of electrical events between smooth muscle. The formation of gap junctions is involved in this phenomenon, and is regulated by oestrogens and prostaglandins [32,33]. It has been shown, that the regulation of the gap junction formation is different for the two layers of the myometrium [34]. A similar difference could also exist between the myometrium and cervical muscular layer which would explain the difference between changes of RMS values and EMG amplitudes of myometrium and cervical muscular layer.

Thirdly, the frequency of the bursts of EMG activity in the cervical muscular layer was lower than in the myometrium. This agrees with a study in parturient cows that showed a decline in the frequency of contractions from the uterine horn towards the uterine body [31]. Although the parturient uterus may be considered as a functional syncitium [35,36], not all contractions that originate at the tip of the uterine horn will reach the uterine body and the cervix. This results in lower contraction frequencies at more caudal sites of the genital tract. A possible functional significance of this phenomenon is to create a pressure gradient within the uterus that enables the uterus to evacuate itself, even after expulsion of the calf. In the cow, the propagation of contractions from the tubal end to the cervical end of the uterus takes some $25 \mathrm{~s}$, depending on the stage of calving [31]. This explains why we found that, although bursts of EMG activity of the myometrium and cervical muscular layer were positively correlated, they had a low correlation coefficient compared to the one (0.6) that what has been reported by Bajcsy et al. [14]. The latter authors determined the postpartum EMG activities at two sites along the longitudinal axis of the myometrium, with a distance of approximately $30 \mathrm{~cm}$ between the electrodes.

Fourthly, the frequency of bursts decreased in the cervical muscular layer, but remained high in the uterus which is in accordance with earlier reports from cows with retained placentas $[13,20]$. It has been shown before that the cervix displays its own contractility pattern during parturition and that its response to prostaglandin $\mathrm{E}$ and oxytocin differs from that of the uterus [22,24,37]. Our study shows that such differences in contractility also exist after parturition and further emphasizes that the cervix has to be regarded as an organ with an own function and acting partly independent of the uterus.

\subsection{The relationship between EMG activity and cervical diameter}

One of the aims of the present study was to investigate to which extent the cervical muscular layer or myometrial activity influences the diameter of the cervix during the early postpartum period. Immediately and shortly after fetal expulsion, EMG bursts of the myometrium and cervical muscular layer were accompanied by transient increases of the cervical diameter. This reflects a cervical tissue that is still soft and pliable. It also suggests that during this early postpartum period, contractions of the uterus and cervix facilitate the expulsion of the (retained) fetal membranes, by a combination of reducing the uterine cavity and instantly increasing the cervical diameter. The gradually decreasing cervical diameter after $15 \mathrm{~h}$ postpartum and the decreased magnitude of the temporal cervical dilatations during contractions point to a more rigid state of cervical tissue, but could also follow from a combina- 
tion of a weaker uterine contractility and a less frequent cervical muscular activity. Our observation that changes in the cervical diameter had a stronger positive correlation with the EMG activity of the cervical musculature than with that of the myometrium, suggests that during the early postpartum period cervical contractions are more important to keep the cervix open than myometrium contractions, while the latter primarily cause a pressure build up and facilitate expulsion of the uterine content. But regarding the weak nature of the correlations, it is likely that other factors may play a more decisive role in the regulation of the cervical diameter postpartum.

With this study, we have demonstrated that in cows with retained placentas cervical closing during the first 2 days postpartum takes place over two stages and that the cervical diameter is influenced by cervical and uterine contractions. However, more study is needed to assess the causal relationship between cervical and uterine contractions and the cervical diameter.

\section{References}

[1] Hafez ESE. The comparitive anatomy of the mammalian cervix. In: Blandau RJ, Moghissi K, editors. The biology of the cervix. Chicago: The University of Chicago Press; 1973. p. 23-56.

[2] Winkler M, Rath W. Changes in the cervical extracellular matrix during pregnancy and parturition. J Perinat Med 1999;27:45-60.

[3] Breeveld-Dwarkasing VN, te Koppele JM, Bank RA, van der Weijden GC, Taverne MA, van Dissel-Emiliani FM. Changes in water content, collagen degradation, collagen content, and concentration in repeated biopsies of the cervix of pregnant cows. Biol Reprod 2003;69:1608-14.

[4] Kleissl HP, van der Rest M, Naftolin F, Glorieux FH, de Leon A. Collagen changes in the human uterine cervix at parturition. Am J Obstet Gynecol 1978;130:748-53.

[5] Conrad JT, Hoover P. Variations in the mechanical behavior of the rabbit cervix with endocrine state and anatomic site. Am J Obstet Gynecol 1982;143:661-6.

[6] Saito M, Kozuma S, Kikuchi A, Sakai M, Fujii T, Unno N, et al. Sonographic assessment of the cervix before, during and after a uterine contraction is effective in predicting the course of labor. Ultrasound Obstet Gynecol 2003;22:604-8.

[7] Bekana M, Jonsson P, Kindahl H. Bacterial isolates associated with retained fetal membranes and subsequent ovarian activity in cattle. Vet Rec 1997;140:232-4.

[8] Bekana M, Jonsson P, Kindahl H. Intrauterine bacterial findings and hormonal profiles in post-partum cows with normal puerperium. Acta Vet Scand 1996;37:251-63.

[9] Berchtold M, Rusch P. Erkrankungen der zervix. In: Grunert E, Berchtold M, editors. Fertilitatsstorungen beim weiblichen rind. Berlin: Parey buchverlag; 1999. p. 209-13.

[10] Roberts SJ. 2nd ed., Veterinary obstetrics and genital diseases (theriogenology), vol. 1, 2nd ed. Ithaka, New York: Roberts, S.J.; 1971. p. 376-544.

[11] Sallam HN, Abdel-Dayem A, Sakr RA, Sallam A, Loutfy I. Mathematical relationships between uterine contractions, cervi- cal dilatation, descent and rotation in spontaneous vertex deliveries. Int J Gynaecol Obstet 1999;64:135-9.

[12] Bajcsy AC, Szenci O, Doornenbal A, van der Weijden GC, Csorba C, Kocsis L, et al. Characteristics of bovine early puerperal uterine contractility recorded under farm conditions. Theriogenology 2005;64:99-111.

[13] Venable JH, Mc DL. Postparturient bovine uterine motility; normal and after experimentally produced retention of the fetal membranes. Am J Vet Res 1958;19:308-13.

[14] Bajcsy AC, van der Weijden GC, Doornenbal A, BreeveldDwarkasing VN, de Jong RC, Szenci O, et al. Validation of pressure measurements and electromyographic results for the uterus of cattle during the early postpartum period. Am J Vet Res 2005;66:1605-15.

[15] Breeveld-Dwarkasing VN, Struijk PC, Eijskoot F, Lotgering FK, van Dissel-Emiliani FM, van der Weyden GC, et al. Ultrasonic cervimetry to study the dilatation of the caudal cervix of the cow at parturition. Theriogenology 2002;57:1989-2002.

[16] Bajcsy AC, Szenci O, Weijden GC, Doornenbal A, Maassen F, Bartyik J, et al. The effect of a single oxytocin or carbetocin treatment on uterine contractility in early postpartum dairy cows. Theriogenology 2006;65:400-14.

[17] Zerobin K, Sporri H. Motility of the bovine and porcine uterus and fallopian tube. Adv Vet Sci Comp Med 1972;16:303-54.

[18] Kundig H, Thun R, Zerobin K, Bachmann B. The uterine motility of cattle during late pregnancy, labor and puerperium. I. Spontaneous motility. Schweiz Arch Tierheilkd 1990;132:7784.

[19] Oshima K, Takenaka A. The effect of prostaglandins on the electromyogram and motility of the monkey uterus and oviduct in late pregnancy and postpartum. J Med Primatol 1977;6:87-98.

[20] Martin LR, Williams WF, Russek E, Gross TS. Postpartum uterine motility measurements in dairy cows retaining their fetal membranes. Theriogenology 1981;15:513-24.

[21] Cibils LA, Hendricks CH. Uterine contractility on the first day of the puerperium. Am J Obstet Gynecol 1969;103:238-43.

[22] Toutain PL, Garcia-Villar R, Hanzen C, Ruckebusch Y. Electrical and mechanical activity of the cervix in the ewe during pregnancy and parturition. J Reprod Fertil 1983;68:195-204.

[23] Pajntar M, Leskosek B, Rudel D, Verdenik I. Contribution of cervical smooth muscle activity to the duration of latent and active phases of labour. Bjog 2001;108:533-8.

[24] van Engelen E, Taverne MA, Everts ME, van der Weijden GC, Doornenbal A, Breeveld-Dwarkasing VN. EMG activity of the muscular and stromal layer of the cervix in relation to EMG activity of the myometrium and cervical dilatation in PGF2alpha induced parturition in the cow. Theriogenology 2007;67:115867.

[25] Wehrend A, Failing K, Bostedt H. Cervimetry and ultrasonographic observations of the cervix regression in dairy cows during the first 10 days post partum. J Vet Med A Physiol Pathol Clin Med 2003;50:470-3.

[26] Edmonson AJ, Lean IJ, Weaver LD, Farver T, Webster G. A body condition scoring chart for Holstein Friesian dairy cows. J Diary Sci 1989;72:68-78.

[27] Breeveld-Dwarkasing VN, Struijk PC, Lotgering FK, Eijskoot F, Kindahl H, van der Weijden GC, et al. Cervical dilatation related to uterine electromyographic activity and endocrinological changes during prostaglandin $\mathrm{F}$ (2alpha)-induced parturition in cows. Biol Reprod 2003;68:536-42.

[28] Naaktgeboren C, van der Weyden GC, Klopper PJ, Kroon CH, Schoof AG, Taverne MA. Electrophysiological observations of 
uterine motility during the oestrous cycle in sheep. J Reprod Fertil 1973;35:511-8

[29] Eijskoot F, Storm J, Kok F, Wallenburg H, Wladimiroff J. An ultrasonic device for continuous measurement of cervical dilation during labor. Ultrasonics 1977;15:183-5.

[30] McCaughey WJ, Patterson AD. Vaginal electrical resistance in cows. 2. Relationship to milk progesterone concentrations during the reproductive cycle. Vet Res Commun 1981;5:77-84.

[31] Burton MJ, Dziuk HE, Fahning ML, Zemjanis R. Myometrial activity during natural and dexamethasone-induced parturition in the cow. Am J Vet Res 1987;48:37-44.

[32] Verhoeff A, Garfield RE, Ramondt J, Wallenburg HC. Electrical and mechanical uterine activity and gap junctions in peripartal sheep. Am J Obstet Gynecol 1985;153:447-54.

[33] Verhoeff A, Garfield RE, Ramondt J, Wallenburg HC. Electrical and mechanical uterine activity and gap junctions in estrogen- treated oophorectomized sheep. Am J Obstet Gynecol 1986;155: 1192-6.

[34] Doualla-Bell F, Lye SJ, Labrie F, Fortier MA. Differential expression and regulation of connexin-43 and cell-cell coupling in myocytes from the circular and longitudinal layers of bovine myometrium. Endocrinology 1995;136: 5322-8.

[35] Lye SJ, Freitag CL. An in-vivo model to examine the electromyographic activity of isolated myometrial tissue from pregnan sheep. J Reprod Fertil 1988;82:51-61.

[36] Lye SJ, Freitag CL. Local and systemic control of myometrial contractile activity during labour in the sheep. J Reprod Fertil 1990;90:483-92.

[37] Hollingsworth M, Isherwood CN. Mechanical responses of the isolated cervix and uterine horn of pregnant rats near term to drugs. Br J Pharmacol 1978;63:513-8. 